\title{
Matošev Cvijet sa raskršća - alegorijom do konfiguracije sebstva
}

\begin{abstract}
Pšihistal Ružica, Matošev Cvijet sa raskršća - alegorijom do konfiguracije sebstva (Matoš's Cvijet sa raskršća [Flower from the Crossroads] - Through Allegory to the Configuration of Self). „Poznańskie Studia Slawistyczne” 7. Poznań 2014. Publishing House Science and Innovate, pp. 185-196. ISBN 978-83-63795-79-5. ISSN 2084-3011.

Flower from the Crossroads (1902) belongs to the group of Matoš's symbolistic novellas, rendered by the symbolically coded title, teleogenetic plot, characters as personified abstractions, motive topography (path, crossroads, garden) and especially the name of the protagonist (Solus). The name Solus, as an autofictional figure, contains its own glossary and reading instructions towards the solipsistic narrative matrix, which is supported by the diegetic level of the story through unusual events bordering dream and reality. With the help of the basic guidelines of Paul Ricoeur on storytelling as a hermeneutical mediation of the self and narrative analysis of the story, the main question of the allegorical interpretation in this study is: which model of self is offered by the narrative identity of Solus?
\end{abstract}

Keywords: Antun Gustav Matoš; Cvijet sa raskršća; self; allegory; flaneur's subjectivity

Ne žalite, ne tugujte za očima, lijepa Izabelo. Čovjek vidi da ne vidi i žali što je vidio. Kada hoću da gledam, zatvaram oči kao vi i gledam u tminu, u sebe.

A.G. Matoš, Cvijet sa raskršća

\section{Uvod}

Simbolički kodiran naslov, teleogenetički zaplet čvrste narativne konfiguracije, likovi kao personificirane apstrakcije (Izabela, Avantira, Izabelin otac i dvorjani), motivska topografija (put, raskrižje, vrt) i posebice ime glavnog lika/pripovjedača (Solus) potvrđuju pripadnost Cvijeta sa raskršća 
krugu Matoševih simbolističkih novela. Postoji, dakle, znakovlje koje nalaže alegorijsko čitanje i ono će u ovoj studiji započeti - u odmaku od pretrage za izvornom autorskom nakanom, kao i od „prevođenja” figurativnog smisla u doslovno značenje - od imena naratorskog lika. Determiniran imenom, Solus je i subjekt i objekt pripovijedanja, čime je otvoren hermeneutički krug samorazumijevanja i samotumačenja. Uz pomoć temeljnih smjernica Paula Ricoeura o pripovijedanju kao hermeneutičkom posredovanju sebstva, inicijalne naratološke raščlambe priče i izdvajanja njezinih nosećih figura, naše je alegorijsko čitanje vođeno pitanjem: kakav model sebstva nudi narativni identitet Solusa.

\section{Solus}

Time što je Cvijet sa raskršća pripovjedni tekst u prvom licu, nije, dakako, zajamčeno da ima autobiografski status. Naprotiv, opće je naratološko mjesto kako se zamjenica ,ja" u fikcionalnim tekstovima odnosi na pripovjedača, na glas koji pripovijeda, nipošto na autora teksta. Ime glavnog lika (solus - sâm, jedini) osigurava od nesporazuma i upućuje da je pripovjedni svijet autentično fikcionalan, no upravo ono na poseban način dovodi do presijecanja triju instancija - autora, pripovjedača i lika te klizanje prema autofikcijskom polu. „Ja” koje izgovara Solus, kao mentalna konstrukcija, ostaje fiktivno, ali svjesna kameleonska dvoznačnost leži pred čitateljem koji odnekud ipak zna da Solus nije ni Matoš, a niti itko drugi. Međutim, osim paratekstualne oznake u posveti (Gđici O.H.) ${ }^{1}$ ova novela ne nudi izravne autobiografske smjernice na površinskoj dijegetskoj razini, a u priči o Solusu ne pripovijeda se o mogućim ili vjerojatnim događajima koji pripadaju svjesnoj javnosti već o neobičnom, snovitom događaju na granici sna i zbilje. Simulacija ,ugovora” između autora, pripovjedača i lika, smještena je dakle na dubinskoj simboličkoj razini teksta u odmaku od standardnih autobiografskih strategija.

1 Olga Herak, Matoševa zaručnica. Matoš je u prvom izdanju novele u sarajevskoj „Nadi” (1902/VIII, 9, 119-122) uz novelu Cvijet sa raskršća imao moto: Alaj je tvrd put (Dante), koji je u Umornim pričama (1909) izostavljen i zamijenjen posvetom Gđici O.H. Cf. napomenu D. Tadijanovića (Matoš 1973a: 305). 
Solus već svojim imenom najavljuje okret prema samome sebi. Njegovo ime odgovara na pitanje pripovjedača, ali fikcionalnim posredovanjem i na pitanja autora: tko sam ja? Jedini, sâm. Kao zamjenički pridjev, leksem solus odgovara također na pitanje: kakav sam ja? te donosi obavijest o karakteru subjekta - ethosu u aristotelovskom smislu. Usamljen. Solus je, dakle, jedini, onaj koji je samo jedan, onaj koji je usamljen u svojoj vrsti ${ }^{2}$. Kao oblik mitopoetskog imenovanja, ime glavnog lika, kako je zabilježeno još u srednjovjekovnim moralitetima, determinira njegovu sudbinu. No ime glavnog lika u Matoševoj noveli nije personificirana apstrakcija vrlina ili grijeha kao u srednjovjekovnim moralitetima, nego znak koji sadrži vlastitu glosu, naputak tumačenja. U bliskoznačnosti s pokaznom zamjenicom ipse (sâm, sâm po sebi), ime Solus sugerira solipsističku matricu pripovijedanja u kojoj je kronotop priče određen sadržajem svijesti naratorskog lika. Solusovo ime, kao autofikcijska figura, najavljuje ,ispovjedni višak” pogodan za tvorbu narativnog identiteta u rikerovskom smislu kojom bi se mogao zatvoriti hermeneutički krug samorazumijevanja i samotumačenja.

\section{Solus pripovijeda sebe}

Sebstvo, prema Ricoeuru, nije neposredno dano, ono je zadaća koja se ne može ostvariti neposrednom introspekcijom³ ${ }^{3}$, nego traži hermeneutičku zaobilaznicu (Brnčić 2008: 732). Descartesov aksiom Cogito sum ostaje prazna i apstraktna istina ako nije posredovana naporom i željom tumačenja (Ricoeur 2005: 49-51). Refleksija shvaća svoju nemoć da prevlada apstrakciju samospoznaje subjekta kao opstojećega i mislećega po sebi i upućuje poziv tumačenju:

2 Onomastička igra sadržana je i u Izabelinu pitanju Solusu: „A zašto putujete ovako sami i samoćni?" (Matoš 1973a: 262).

3 Introspektivnost radikalne refleksivnosti, poziv prema unutra, unutarnjem čovjeku u kojem počiva istina, uveo je sv. Augustin i ostavio je u nasljeđe zapadnoj misaonoj tradiciji. Iz toga je proistekla moderna epistemološka tradicija od Descartesa nadalje. Augustin je izumitelj argumenta koji poznajemo kao cogito, jer je on bio prvi koji je učinio perspektivu prvog licu temeljnom u našoj potrazi za istinom (cf. Taylor 2011: 139-153). 
Ovdje refleksija poziva tumačenje i želi se prometnuti u hermeneutiku. To je konačan korijen našeg problema: on počiva na ovoj iskonskoj povezanosti čina postojanja i znakova koje razvijamo u našim djelima; refleksija mora postati tumačenje, jer ja čin postojanja ne mogu zahvatiti drukčije nego u znakovima porazbacanima u svijetu (Ricoeur 2005: 52).

U hermeneutičkim zaobilaznicama kojima subjekt spoznaje sebe, priča ima povlašteno mjesto: sebstvo se konstituira posredstvom priče (cf. Ricoeur 2000a: 20, Brnčić 2008: 732-736) . Gradnja zapleta omogućuje integraciju različitosti, promjenjivosti, diskontinuiteta u „suglasju nesuglasja” priče koja slučajnosti preobražava u sudbinu (Brnčić 2008: 733). Kroz tvorbu narativnog identiteta dostižemo samorazumijevanje sebe. Konfiguracija sebstva odvija se konfiguracijom narativnog identiteta glavnog lika uz pomoć zapleta (cf. Ricoeur 2000b: 58). Identitet lika gradi se u odnosu na identitet zapleta kroz križanje i međuprožimanje istosti (idem, jedno te isto) $\mathrm{i}$ istovjetnosti (ipse, sam po sebi) ${ }^{5}$, odgovarajući na pitanje kako je moguće da se čovjek neprestano mijenja i pri tome ostane isti.

Solus je i subjekt i objekt pripovijedanja. Priča o Solusu svojevrsno je pripovijedanje sebstva, pri čemu Solusov okret prema samome sebi u nutrini samopromatranja ne ide u pravcu dostizanja pune i savršene kartezijanske samosvjesnosti u kojoj cogito ima „neograničenu vlast” (Taylor 2011: 167-169) i gdje postoji puna svjesnost sebe, nego smjera otvaranju tamnih prostora koji izmiču nadzoru svjesnog Ja: „Ne žalite, ne tugujte za očima, lijepa Izabelo. Čovjek vidi da ne vidi i žali što je vidio. Kada hoću da gledam, zatvaram oči kao vi i gledam u tminu, u sebe" (Matoš 1973a: 262).

${ }^{4}$ Samonaracija kao način na koji čovjek u bilo kojem vremenu nalazi svoj identitet, kod modernog subjekta počiva na razvijanju priče iz događaja, a ne na temelju tradicionalnih modela, arhetipova i prefiguracija. Mi postajemo ono što jesmo kroz događaje o kojima pripovijedamo (cf. Taylor 2011: 301-302).

5 Dok istost (idem) označuje nepromjenjivu identičnost, permanentnost $\mathrm{u}$ vremenu, numerički odnos jednosti (bivanja jednim te istim sa samim sobom), istovjetnost (ipse) označuje kvalitativni identitet, odnos krajnje sličnosti (bivanje samim po sebi). Istost (idem) označuje biti isto sa sobom, dok istovjetnost (ipse) znači biti isto sa sobom po sebi (cf. Ricoeur 2000a: 20-21; Brnčić 2008: 733; Vodičar 2011: 87). 


\section{Sa zatvorenim očima}

Pripovjedač u prvom licu nastupa in medias res te jamči, kako je to zapazio Ivo Frangeš, ,ispovjednu prisnost” (Frangeš 1986: 191). Osobni pripovjedač koji raspolaže tjelesnim jastvom objavljuje se već u prvoj rečenici: „Umoran stignem u južni francuski gradić N.”. Tjelesnost pripovjedača u prvom licu, koju je Stanzel označio ključnim čimbenikom razlike prema pripovijedanju u trećem licu (cf. Stanzel 1992: 189-198), dovodi do njegova egzistencijalna usidrenja u svijetu likova i to je razlogom da se vrijeme života (Zeiterlebnis) ne da staviti izvan igre, a odnos između autora i pripovjedača u prvom licu ostao je trnovitim područjem naratologije (cf. Genette 2002: 56).

Solus je taj koji pripovijeda i koji doživljava, on je tjelesno nazočan na mjestu događaja o kojemu pripovijeda. Orijentacijski sustav uvodne opisne figure (hipotipoze) izgrađen je oko vidnog i slušnog polja naratorskog lika i ostaje urušen u sadašnjost čina pripovijedanja:

Tišina mi u uhu. Suvarak je bez šuškavog sljepića, zrak bez ose i bumbara. Prhnu vrapčić, moj stari pratilac i lakomi poznanik, otrvši na mahovini proždrljivi kljun. Iz gradića se zatalasa bakarno podne i prosu sunčanom okolinom još veću tišinu, svečani mir blagdana (Matoš 1973a: 259).

Vrijeme pripovijedanja započinje prezentom, pripovijedanje je istodobno dijegetskom vremenu, vrijeme junakove priče istodobno je sadašnjosti pripovijedanja i rastegnuto, sljubljeno s tjelesnim ,sada" pripovjedača. Stilogena igra s prošlim vremenskim oblicima (aorist, imperfekt, perfekt) ${ }^{6}$, ne odvaja događaje od glasa koji pripovijeda. Budući da nema odmaka niti vremenske distance između pripovjedača i onoga o čemu pripovijeda, pripovjedač je krajnje nepouzdan, što je s druge strane razlogom zašto mu vjerujemo ${ }^{7}$. Simbioza lika i pripovjedača koji pripovijeda ,sada” i „ovdje” dovodi do čudne utrke s vremenom, jer pripovjedno „sada” ostaje stopljeno s dijegetskim

${ }^{6}$ Matoševu igru s vremenskim oblicima (prezent, aorist, imperfekt, perfekt) Frangeš opisuje kao ,glazbenu kompoziciju, violinski, gudački largo” (Frangeš 1986: 196).

7 „Pouzdanost pripovijesti o sebi ovisi o vremenskome razmaku između pripovjedača i onoga o čemu se pripovijeda, ali mora žrtvovati iskrenost pripovjedne samosvijesti da bismo toj pripovijesti vjerovali" (Currie 2002: 193). 
vremenom, a da nužno kasni za pričom. Ispričana priča uvijek je prošlost pripovjednog glasa (Ricoeur 1987: 95), dok ,vrijeme priče (onoga što je ispripovijedano) ubrzano sustiže vrijeme pripovijedanja" (Currie 2002: 193). To „sada” koje neumitno teče s pripovijedanjem i prati kronološko vrijeme, od podnevne „sieste”, kada je Solus stigao do aleje nedaleko ljetnikovca, do ponoći kada odlazi, oznaka je nedohvatljive ništeće sadašnjosti u srazu $\mathrm{s}$ unutrašnjim, fenomenološkim vremenom priče koje u konačnici teži negaciji svake protočnosti ${ }^{8}$. Vrijeme priče ostaje zamrznuto, snoliko svevremeno sada koje svoju vremenitost ne duguje kronološkom vremenu, nego je smješteno unutra, ,ispod zatvorenih očiju”: „Časovi oslijepiše, vrijeme prestade teći i rušiti” (Matoš 1973a: 262). Ostaje tako dvojbenim je li Solus doista otvorio oči kada je ugledao Izabelu, ili nam pripovijeda - dok tijelo miruje priču čiji se zaplet gradi iz točke koja nije u (kronološkom) vremenu.

\section{Gramatika sna}

Događaj se odigrava poslije buđenja glavnog lika, ali već uvodna hipotipoza donosi tipično matoševsku inscenaciju miješanja sna i stvarnosti ${ }^{9}$. U imaginariju fokalizatora na granici vizije miješaju se elementi realnoga i irealnoga udruženi s literarnim asocijacijama podrijetlom iz pastoralnoga tematsko-stilskog kompleksa i bakhantskoga dionizijevskog kulta s libidinoznim simboličkim potencijalom:

Cvijeće pjeva mirisom tratinčica i ivanjskog cvijeća šaren pastorale. Jezero šumi srebrnu himnu, iz tamnih šuma bruje crni koralji. Nebo šušti zastavom od modre svile. Iz dubine grmlja, gajeva i gore skaču razigrane djevojke, šibajući uzduh znojnom,

${ }^{8}$ Cjelokupno moderno, egzistencijalno promišljanje vremena (Husserl, Heidegger, Sartre) proizašlo je iz Augustinove fenomenologije „unutarnjeg vremena”, prema kojoj vremenske instancije nisu bića, nego načini na koje se stvari prikazuju svijesti, duhu. Duh je taj koji određuje, mjeri vrijeme kao sadašnjost u prošlosti (pamćenje), sadašnjost u sadašnjosti (gledanje) i sadašnjost u budućnosti (očekivanje) u latentnoj igri s odsutnošću: više ne prisutno, još ne prisutno, sada-ovdje prisutno u nedohvatljivoj sadašnjosti (cf. Lyotard 2010: 33, 49, 63, 91-92).

9 Prema tipologiji Matoševe poetike sna, Cvijet sa raskršća pripada drugom tipu simbolističkih novela u kojima su san i zbilja paralelni svjetovi, svjetovi sna ostaju bez dodira sa zbiljom, nedosegnuti ideali (cf. Oraić Tolić 2013: 233-237). 
bahantskom kosom. Kao nabujala bujica struje u bučnoj, krvavoj orgijskoj pjeni niz glasnu goru i kotlinu, a u njoj graja, bleka stoke, duduk gajda kroz pastirski dim, kroz satirsko, vinsko jecanje od požude, kroz Jareće drhtavo, požudno blejanje (Matoš 1973a: 259-260).

Mjesto u blizini nepoznatoga francuskog gradića N. ujedno je mjesto uživanja, „ljupki krajolik” (locus amoenus), koliko i „užasno mjesto” (locus horridus) s amblematskim likom Gorgone. Heterotopijska konfiguracija pejsaža sugerira fantazmagorični onirički ustroj. Na paradigmatskoj i sintagmatskoj osi opisa sudaraju se nespojive i heterogene komponente koje se isključuju prema elementarnim logičkim načelima. Zadana linearnost verbalnog izričaja u sukobu je sa simultanošću opisnih jedinica, što dovodi do gubitka jasnoga vremenskog orijentacijskog uporišta. U nastavku priče u okvirno sublimni prizor s primarnim estetskim registrom bjeline i secesijske ornamentalnosti ulaze trivijalni, groteskni i bizarni detalji bodlerovske i poovske motivske topografije: muha dosadno slijeće na Solusov nos u isto vrijeme dok se Izabela nadvila nad njegovim licem; dok Solus cjeliva Izabelinu „bijelu cipelicu” i ,svilenu, modru čarapu”, pas mu liže glavu „tankim jezikom”; Izabelin otac spominje vampira Vachera i Jacka Trbosjeka o kojima je upravo čitao u dnevnom tisku. Deskriptivne i dijegetske jedinice priče ustrojene su na način piktografskog scenarija čiji manifestni sadržaj traži prijevod u neki drugi znakovni sustav. Gramatika sna primorava nas na izručenje u prostor latentnoga i neizrečenoga. San je arhetipski uzorak priče koja zahtijeva alegorezu. Temeljna Freudova teza da san ima značenje i da se priča sna može zamijeniti nekom drugom pričom s korelativnom semantikom i sintaksom (cf. Ricoeur 2005: 96) oslanja se upravo na taj hermeneutički model:

Upravo san, ostavimo po strani cijelo pitanje škole, potvrđuje da neprestano želimo reći nešto drugo od onoga što kažemo; postoji očitovano značenje koje ne prestaje upućivati na skriveno značenje, ono što svakog sanjača čini pjesnikom (Ricoeur 2005: 22).

\section{Znakovno preobilje - alegorija}

Linearna narativna logika koja se razvija iz središnjeg događaja - susret s Izabelom - nudi jednostavan ključ čitanja, dok u isto vrijeme nalaže 
ponovljena čitanja koja neće biti upravljena pitanjem što se dogodilo, nego koji skriveni smisao leži iza ispripovijedanoga ${ }^{10}$. Narativna logika prividno je netaknuta, ali je istovremeno i nezadovoljavajuća, kao i pretpostavka da se radi o svestrano motiviranim junacima, psihološkim tipovima ili temeljito prikazanim moralnim karakterima. Takvoj zatvorenoj i umreženoj čvrstoj znakovnoj konfiguraciji odgovara narativni model parabole, koji nalaže vraćanje skrivenoj jezgri priče. Nizom znakovlja čitatelj je primoran tražiti drugi i drukčiji smisao, ali i da to znakovlje hermeneutičkom rekonstrukcijom poveže u novu cjelinu s drugim smislom. Nije dakle posrijedi, u Freyeovu smislu, „pripovjedačko djelo" u užem smislu, nego ,priča” u kojoj dominira ideja, misao (dianoia) kojoj je fabula tek vanjski omotač (cf. Frey 1979: 66-68). Obvezatan prijelaz na „drugi” smisao uz pomoć reinterpretacije i obnavljanja čitanja s one strane površnog procesiranja podataka označuje alegoriju kao figuru čitanja, a ona je korelativno upisana u samome tekstu alegorijskim narativno-deskriptivnim strategijama. Uz teleogenetički zaplet zatvorene strukture, vidljivi su i drugi alegorijski signali: simbolički kodiran naslov, pripovjedni svijet naseljen personificiranim apstrakcijama ${ }^{11}$ (Izabela i Avantira, Izabelin otac i dvorjani kao prijeteći Drugi), uvod s oniričkim okvirom, obrazac putovanja, raskrižje, vrt (cf. Stamać 1995: 255-256; Kurz 1997: 46-50; Tambling 2010: 7-8). Ukratko, za puno razumijevanje Solusove priče nužan je prijelaz na drugu razinu značenja. Konačno, alegorijski je modus vidljiv u finalnoj nečitljivosti teksta (de Man 1979: 202), tvrdokornom otporu k jednoznačnom tumačenju i pojačanom pozivu na ponavljajuća ,pogrješna” čitanja.

Raskorak između izgovorenoga i mišljenoga, manifestnoga i latentnoga, priziva uvijek nova čitanja bez jednoznačnih i konačnih alegorijskih ekvivalencija. Matoš nastupa kao moderni alegoričar koji nalaže tumačenje, ali mu u isto vrijeme iskazuje otpor i ne propisuje smjer, ugrađujući u znakovni sustav trajnu značenjsku odgodu ${ }^{12}$. Kao što je na primjeru barokne žalobne

${ }^{10}$ Od tekstualnih pokazatelja koji pokreću alegorijsko tumačenje najčešći su proturječnost, anakronizmi, nevjerojatnost, suvišnost ili apstraktna jednostavnost (cf. Kurz 1997: 16-20, 60-62).

11 Povijest alegorije kao narativnog žanra započinje s Prudencijem, koji je spjevom Psihomahija usvojio personifikaciju kao vodeće narativno kompozicijsko načelo (cf. Whitman 1987: 84-91).

12 Mehanizam značenjske odgode počiva na nemogućnosti da se u nepovratno razgrađeni svijet unese konačni smisao putem jednoga interpretativnog sklopa, budući da se jedanput dokučeni smislovi ponovno pretvaraju u šifre (cf. Biti 1997: 5). 
igre pokazao Walter Benjamin, a kasnije je radikalizirano u de Manovim dekonstrukcijskim čitanjima, alegoričar ne može povratiti smisao u nepovratno razgrađeni i fragmentirani svijet: Alegorije su u carstvu misli, ono što su ruine u carstvu stvari (Benjamin 1989: 139).

\section{Flaner koji bježi iz gradova}

Figuru flanera (fr. flâneur), kao tipično impresionistički proizvod urbane kulture i estetike ulice, Matoš je uveo u hrvatsku književnost. Flanerija je u užem smislu tipično urbana praksa koja podrazumijeva rafiniranu, neutilitarnu šetnju (Nemec 2010: 75). Flaner je čovjek koji dokono tumara gradom bez selekcije i ideoloških poruka (Oraić Tolić 2013: 35), čovjek urbanog mnoštva s asocijalnim mentalnim habitusom (cf. Benjamin 1986: 48, 54).

Solus nije dokoni gradski šetač - flaner, nego putnik nalik ,prosjaku ili vandrokašu" koji putuje sâm i bježi iz gradova. O tomu svjedoči precizna autoidentifikacija: „Ja sam putnik. Putujem pješke oko svijeta. Što je lijepo, uhvatim fotografskim aparatom. To je jedini zanat koji znam" (Matoš 1973a: 262).

Flanerizam ne pripada, dakle, površinskim diskurzivnim očitovanjima Solusa kao pripovjednog lika. Solusov je karakter ${ }^{13}$ dubinski obilježen flanerizmom, točnije flanerističkom subjektivnošću. On putuje u želji da „uhvati” nešto lijepo upravo fotografskim aparatom kao produženim flanerskim okom. Avantiri, čijem se vodstvu s krajem priče prepušta Solus, Matoš je u svojem feljtonu (Flanerija) dao ulogu vodeće muze egzistencijalno-estetskog flaniranja:

I flanerija je riječ neprevedljiva poput svih koje označuju viša, rafinovana uživanja.

Riječ šetati znači u narodnoj našoj pjesmi nešto ukočeno, gospodsko, dok je flaniranje zabava bezbrižna, ležerna, regbi demokratska. Šetalac ima cilj, zna kamo i zašto ide, šetanje je kretanje obično higijensko, utilitarističko, dok je flâneur umjetnik,

${ }^{13}$ Pod karakterom se podrazumijeva skup razlikovnih oznaka koje dopuštaju da se reidentificira ljudska jedinka kao jednaka samoj sebi u preklapanju numeričkog idem i kvalitativnog ipse identiteta, označujući kontinuitet u promjenama i trajnost u vremenu (cf. Ricoeur 2000a: 25-29). 
svrha mu je flaniranje - l'art pour l'art. Vodi ga slučaj, avantira, poezija (Matoš 1973b: 202).

Kao paradoksalna figura flanera koji ne flanira (gradom), Solus je u trajnom, egzistencijalnom flaniranju s naglašeno estetskim karakterom lutanja u potrazi za lijepim i neposrednim doživljajem, kao i s uplivom romantičarske figure „,nesretne lutalice” u ideji eskapizma - bijega od zbilje i ropskog življenja u gradovima: „Zato bježim iz varoši i kružim sam, slobodan kao soko. Ovo je teško, ja sam nesrećan, ali živjeti sa ljudima, sa lašcima, bilo bi mi još gorče. Znate li basnu o psu i kurjaku? Ja sam vuk, mršavi, slobodni vuk" (Matoš 1973a: 262). Prostor flanerističke subjektivnosti otvoren je beskonačnom umnažanju liminalnih situacija u otporu prema diktaturi kronološkog vremena (Solus ne zna koji je dan u tjednu i već je davno izgubio kalendar!), kao i prema vlasti instrumentalnog razuma. Kartezijanski cogito, kao instrumentalna racionalnost koja upravlja čovjekovom voljom i kontrolira emocijama, u flanerističkoj je subjektivnosti radikalno osporen. Flaneristička se subjektivnost hrani neposrednim i neselektivnim osjetilnim dojmovima i prihvaćajući fragmentiranost svijeta (Oraić Tolić 2013: 36) korespondira s medijem fotografije kroz kojega ,svijet postaje niz nepovezanih, samostojećih čestica, a povijest, prošla i sadašnja, zbirka anegdota i beznačajnih događaja” (Sontag 2007: 25). Fotografsko viđenje svijeta - kao i flanerizam - razbija ideju o njegovoj sustavnosti i cjelovitosti te negira međusobnu povezanost i slijed, dok u isto vrijeme svakom trenutku daje obilježje zagonetnosti. Kao umjetnost koja je u svojoj srži nadrealistička i koja će svoj puni izraz doživjeti u rukama avangardnih umjetnika, fotografija je odgovarala nadrealističkom zahtjevu za ravnopravnim tretiranjem svih tema i otvorila prostor potencijalno neograničenoj mreži značenja (cf. Sontag 2007: 25).

\section{Gdje je moje mjesto}

Solus se budi u krilu Izabele. Nepredviđeni događaj pred njega je postavio izbore. Ostati s Izabelom i služiti joj umjesto njezine dosadašnje paziteljice/čitateljice; povesti Izabelu sa sobom; nastaviti lutati sâm u pratnji Avantire. O čemu ovisi hoće li pretegnuti jedna, druga ili treća mogućnost? Narativni identitet Solusa, zbijen u njegov karakter, ovisi o njegovoj odluci. 
Solus izabire treći put. No njegov izbor Avantire, ,slobodne i maglovite vile”, samo je privid odluke, jer ona ga je dovela do Izabele i ona ga je čekala pored raskrižja, a jednako je lijepa i jednako slijepa kao Izabela. Kada odvode Izabelu, Solus je trivijalnim i frivolnim opravdanjem cijeli događaj premjestio u područje bunovnog slučaja: „Gospođica je nabasala slučajno, pošto spavah, i ja je nagovarah da se vrati u kuću” (Matoš 1973a: 264).

Umjesto odluke, Solus iskazuje nevoljkost za promjenu, ontološku starost, umorni pristanak na trajnu privremenost, odgađanje odluke s ahasverskim ultimatumom živjeti na putu, od jednog do drugog raskrižja, bez konačnog odredišta. U sukobu s vlastitom voljom - jer ljubi ono što ne želi i želi ono što ne ljubi - Solusova priča, kao predujevićevska ,somnabulna skica” (Pšihistal 2011: 67-79), iskazuje neuspjeh u rekolekciji sebstva, jer je odgovor na pitanje „tko sam?” ovisio o popratnici ili prethodnici tog pitanja: „gdje je moje mjesto?" Solusovo je mjesto ne biti na mjestu u svijetu u kojem su svi događaji - pa i susret s Izabelom, koji ga nakratko punktira do u središe bića - tek plod slučaja (hirovite i slijepe Avantire!). Formula sebstva razotkriva se u negativnom obliku trajne ontološke neodlučnosti modernog subjekta koji ne traži i ne zna gdje je njegovo mjesto, protiv potrebe za kartezijanskim nadziranjem sebstva, u izručenju u prostor nedovršenosti, fragmentiranosti, flanerizma kao egzistencijalne i ontološke označnice. Problematičnost Solusova sebstva nije u prekinutoj, nego u zamrznutoj istosti - nedodirnutosti zapletom. Kao u paraboli, bajci ili „basni o psu i kurjaku”, Solus se s krajem priče može identificirati i reidentificarati kao nepromjenjivi isti. Njegova je sudbina determinirana njegovim karakterom, prokazanim njegovim imenom (Solus).

Figura tjeskobne, okamenjujuće zmijokose Gorgone kao amblem modernog sebstva uokviruje i natkriljuje Solusov svijet. Hermeneutički krug otvoren pripovijedanjem sebstva nije zatvoren. Pripovjedni identitet Solusa prokazuje aporetičnost potrage za supstancijalnim sebstvom, samoću lutanja u svijetu - bez sebe.

\section{Literatura}

Benjamin W., 1986, Estetički ogledi, prev. T. Stamać, S. Knežević, Zagreb.

Benjamin W., 1989, Porijeklo njemačke žalobne igre, prev. J. Finci-Pocrnja, Sarajevo.

Biti V., 1997, Pojmovnik suvremene književne teorije, Zagreb.

Brnčić J., 2008, Ricoeurova hermeneutika sebstva, „Filozofska istraživanja” br. 3, str. 731-747. 
Currie M., 2002, Istinite laži, u: Politika i etika pripovijedanja, ur. V. Biti, Zagreb, str. 191-206.

Frangeš I., 1986, Nove stilističke studije, Zagreb.

Frye N., 1979, Anatomija kritike, prev. G. Gračan, Zagreb.

Genette G., 2002, Fikcija i dikcija, prev. G. Rukavina, Zagreb.

Kurz G., 1997, Metapher, Allegorie, Symbol, Göttingen.

Lyotard J.F., 2010, Augustinova ispovijest, prev. M. Gregorić, Zagreb.

de Man P., 1979, Allegories of Reading: Figural Language in Rousseau, Nietzsche, Ril$k e$, and Proust, New Haven-London.

Matoš A.G., 1973a, Sabrana djela, sv. 1, Iverje. Novo Iverje. Umorne priče, ur. D. Tadijanović, Zagreb.

Matoš A.G., 1973b, Sabrana djela, sv. 5, Pjesme. Pečalba, ur. D. Tadijanović, Zagreb.

Nemec K., 2010, Čitanje grada, Zagreb.

Oraić Tolić D., 2013, Čitanja Matoša, Zagreb.

Pšihistal R., 2011, Ujević i sveti Moničin sin, „Republika” br. 9, str. 58-71.

Ricoeur P., 1987, Iskazivanje - iskaz - predmet u ,, diskurzu pripovjednog teksta”, prev.

A. Zlatar, „Republika” br. 11-12, str. 74-96.

Ricoeur P., 2000a, Osobni i narativni identitet, prev. J. Brnčić, u: Autor, pripovjedač, lik, ur. C. Milanja, Osijek, str. 19-48.

Ricoeur P., 2000b, Ja i narativni identitet, prev. J. Brnčić, u: Autor, pripovjedač, lik, ur. C. Milanja, Osijek, str. 49-81.

Ricoeur P., 2005, O tumačenju, Ogled o Freudu, prev. Lj. Lovrinčević, Zagreb.

Sontag S., 2007, O fotografiji, prev. I. Rončević, Osijek.

Stamać A., 1995, Naziv alegorija (enciklopedijske natuknice o pridruženim pojmovima), u: Tropi i figure, ur. Ž. Benčić, D. Fališevac, Zagreb, str. 253-259.

Stanzel F., 1992, Pripovjedni tekst u prvom i pripovjedni tekst u trećem licu, prev.

M. Stančić, u: Suvremena teorija pripovijedanja, ur. V. Biti, Zagreb, str. 178-200.

Tambling J., 2010, Allegory, The New Critical Idiom, London.

Taylor Ch., 2011, Izvori sebstva, Razvoj modernog identiteta, prev. M. Miladinov, Zagreb.

Vodičar J., 2011, Narrative as a Means of Creating an Identity for Ourselves and Others, „Synthesis philosophica” br. 1, str. 79-91.

Whitman J., 1987, Allegory. The Dynamics of an Ancient and Medieval Technique, Cambridge. 